\title{
Studi Density Functional Theory (DFT) Pengaruh Co-doping Zn dan N pada $\mathrm{TiO}_{2}$ Anatas
}

\author{
Muhammad Shofiyullah*, Wirda Udaibah, Ika Nur Fitriani \\ Program Studi Kimia, Fakultas Sains dan Teknologi, UIN Walisongo Semarang, Indonesia \\ *E-mail: Shofiyullah55@gmail.com
}

\begin{abstract}
Abstrak
Titanium dioksida $\left(\mathrm{TiO}_{2}\right)$ merupakan salah satu bahan yang menjanjikan yang memenuhi persyaratan fotokatalis. Penelitian ini mempelajari pengaruh doping $\mathrm{Zn}$ dan $\mathrm{N}$ pada struktur geometri dan elektronik $\mathrm{TiO}_{2}$ anatas. Untuk mengetahui struktur dan proses kinerja fotokatalitik digunakan perhitungan density functional theory (DFT) dengan algoritma generalized gradient approximation (GGA) menggunakan parameterisasi Perdew-Burke-Ernzerhof (PBEsol). Perhitungan struktur elektronik menggunakan parameter Hubbard $U$. Setelah optimasi terjadi distorsi volume kisi doping Zn 1,011 $\AA$, doping N 1,209 Å dan co-doping Zn-N 1,646 A. Data tersebut menunjukkan bahwa doping dapat mempengaruhi perubahan struktural. Perhitungan struktur elektronik menghasilkan celah pita $\mathrm{TiO}_{2}$ murni sebesar $3,18 \mathrm{eV}$, kemudian terjadi penyempitan celah pita yang disebabkan oleh dopan. Celah pita doping $\mathrm{Zn} 2,9 \mathrm{eV}$, doping N 2,78 $\mathrm{eV}$ dan co-doping Zn-N 2,74 eV. Struktur elektronik baru hasil doping tidak hanya menyebabkan penyempitan celah pita tapi juga dapat menghambat rekombinasi pasangan elektron-hole, secara signifikan dapat meningkatkan aktivitas fotokatalitik $\mathrm{TiO}_{2}$ di daerah cahaya tampak.
\end{abstract}

Kata kunci: Aktivitas Fotokatalitik; Co-doping; $\mathrm{TiO}_{2}$ anatas

\begin{abstract}
Titanium dioxide $\left(\mathrm{TiO}_{2}\right)$ is one of promising material that meets the requirements of photocatalysts. This research studies the effect of $Z n$ and $N$ doping on the geometric and electronic structure of anatase $\mathrm{TiO}_{2}$. To determine the structure and process of photocatalytic performance, density functional theory (DFT) calculations are used with the generalized gradient approximation (GGA) algorithm using Perdew-Burke-Ernzerhof (PBEsol) parameterization. The calculation of the electronic structure used Hubbard U parameters. After optimization, the volume distortion of $\mathrm{Zn}$ doping was 1,011 $\AA$, doping $N$ 1,209 A and $Z n-N$ co-doping 1,646 . These data suggest that doping can affect structural changes. The calculation of the electronic structure resulted in a pure $\mathrm{TiO}_{2}$ bandgap of $3.18 \mathrm{eV}$, then the bandgap narrowing was caused by dopants. Band gap for Zn doping $2.9 \mathrm{eV}, \mathrm{N}$ doping $2.78 \mathrm{eV}$ and $\mathrm{Zn}-\mathrm{N}$ co-doping $2.74 \mathrm{eV}$. The new doping electronic structure not only causes band gap narrowing but can also inhibit the recombination of electron-hole pairs, significantly increasing the photocatalytic activity of $\mathrm{TiO}_{2}$ in the visible light region.
\end{abstract}

Keywords: Anatase $\mathrm{TiO}_{2}$; Co-doping; Photocatalytic activity 


\section{Pendahuluan}

Pengembangan bahan fotokatalitik yang aman, melimpah, dan murah merupakan aspek yang penting dalam mengatasi krisis energi dan lingkungan. Titanium dioksida $\left(\mathrm{TiO}_{2}\right)$ merupakan salah satu bahan menjanjikan yang memenuhi persyaratan fotokatalis. Oleh karena itu, menjadi perhatian luas dalam beberapa tahun terakhir yang digunakan dalam produksi gas hidrogen (Jani et al., 2020), antibakteri (Pragathiswaran et al., 2020) dan sel surya peka warna (DSSC) (Shalini et al., 2020).

$\mathrm{TiO}_{2}$ memiliki tiga polimorf: anatas, rutil dan broonkit. Anatas menunjukkan sifat fotokatalitik, stabilitas fase, dan peningkatan aktivitas fotokatalitik sehingga menjadi fokus utama penelitian ini. Selain itu, $\mathrm{TiO}_{2}$ adalah fotokatalis yang menjanjikan karena stabilitas kimianya, tidak beracun, dan harganya murah. Namun, $\mathrm{TiO}_{2}$ anatas adalah semikonduktor mempunyai lebar celah pita $3,2 \mathrm{eV}$ yang menyerap hanya sekitar $4 \%$ dari cahaya matahari. Selain itu, tingkat rekombinasi pasangan elektron-hole sangat tinggi sehingga kemampuan fotokatalitik $\mathrm{TiO}_{2}$ menjadi menurun (Tehare et al., 2017).

Banyak upaya telah dilakukan untuk mengurangi celah pita serta meningkatkan kinerja fotokatalitik $\mathrm{TiO}_{2}$ di daerah cahaya tampak, seperti doping menggunakan logam transisi (V, Mn, Fe, Cu, Ce, W, Cr, Co, Ag,) (Chang \& Liu, 2014), doping nonlogam (B, N, P, I,) (Kuo et al., 2019) dan deposisi logam mulia (Ag, Pd, Pt) pada permukaan $\mathrm{TiO}_{2}$ (Gomes et al., 2018).

Doping logam dan nonlogam merupakan salah satu metode modifikasi yang paling efektif dan menjadi minat yang besar bagi para peneliti (Schneider et al., 2014). Dalam doping ion nonlogam umumnya menempati posisi oksigen yang menyebabkan sebagian besar pita valensi $\mathrm{TiO}_{2}$ terdiri dari keadaan $02 p$. Orbital $p$ ini akan berpasangan dengan orbital $p$ dopan nonlogam, sehingga menyebabkan keadaan elektronik pengotor di atas pita dan menghasilkan penyempitan celah pita. Perhitungan struktur elektronik $\mathrm{TiO}_{2}$ yang didoping berbagai konsentrasi $\mathrm{N}$ dengan substitusi $\mathrm{N}$ ke situs $\mathrm{O}$ menunjukkan bahwa keadaan pengotor $\mathrm{N} 2 p$ muncul di bagian atas pita valensi dan bercampur dengan keadaan $0 \quad 2 p$ sehingga menyebabkan penurunan celah pita (Wu et al., 2012).

Doping ion logam, terutama logam transisi juga dapat meningkatkan kinerja fotokatalitik $\mathrm{TiO}_{2}$. Pita konduksi $\mathrm{TiO}_{2}$ sebagian besar terdiri dari keadaan Ti $3 d$, yang akan berpasangan dengan orbital $d$ ion logam transisi, sehingga menghasilkan sifat struktur elektronik baru. Kehadiran dopan logam transisi secara signifikan meningkatkan aktivitas fotokatalitik $\mathrm{TiO}_{2}$ serta meningkatkan koefisien absorpsi cahaya. Perhitungan elektronik menunjukkan bahwa orbital $3 d$ dari elemen logam transisi secara dominan mengurangi celah pita. Selain itu, ketika atom Ti digantikan oleh elemen logam transisi $3 d$ dengan diameter atom yang lebih kecil, maka dapat meningkatkan transisi elektronik yang baik (Liu et al., 2018).

Metode lain yang efektif adalah codoping: logam, nonlogam, atau secara bersamaan logam-nonlogam. Co-doping ion $\mathrm{Fe}^{3+}$ dan $\mathrm{Zn}^{2+}$ pada $\mathrm{TiO}_{2}$ menghasilkan sifat fotokatalitik yang lebih baik dibandingkan dengan bahan yang didoping ion besi atau seng saja (Yuan et al., 2018). Contoh lain dari co-doping logam adalah $\mathrm{TiO}_{2}$ yang didoping dengan logam Fe dan Ni (Lin et al., 2017). Ditemukan bahwa co-doping $\mathrm{Fe}$ dan $\mathrm{Ni}$ menyebabkan beberapa keadaan pengotor $\mathrm{Fe} 3 d$ dan $\mathrm{Ni} 3 d$ di celah pita sistem $\mathrm{TiO}_{2}$, yang meningkatkan penyerapan optik $\mathrm{TiO}_{2} \mathrm{di}$ wilayah cahaya tampak dan cahaya inframerah. Efek sinergis dari co-doping Fe dan $\mathrm{Ni}$ menyebabkan penyempitan celah pita. Dengan cara yang sama, aktivitas fotokatalitik di daerah cahaya tampak meningkat dengan co-doping nonlogam (ion nitrogen dan sulfur) dibanding dengan doping tunggal (Chen et al., 2018) 
Penggunaan co-doping logam nonlogam secara signifikan dapat meningkatkan aktivitas fotokatalitik misalnya co-doping $\mathrm{Cr}$ dan $\mathrm{C}$ menyebabkan penyempitan celah pita dan menghambat rekombinasi pasangan elektron-hole sehingga dapat meningkatkan aktivitas fotokatalitik di daerah cahaya tampak (X. Li et al., 2017). Co-doping Zn dan F lebih efisien meningkatkan fotokatalitik di daerah cahaya tampak dan stabilitas yang tinggi dalam degradasi polutan dibanding doping tunggal. Dilaporkan juga oleh Sun et al. bahwa penyerapan di daerah cahaya tampak dan penyempitan celah pita sangat bergantung pada konsentrasi donor-akseptor dopan (Sun et al., 2020).

\section{Co-doping logam-nonlogam} melibatkan penggantian ion titanium dengan kation yang didoping dan ion oksigen dengan anion yang didoping. Oleh karena itu, dopan harus dipilih berdasarkan jari-jari ioniknya. Karena radius seng mendekati radius titanium, seng dianggap dopan yang menjanjikan (Bayan et al., 2020). Ukuran ion nitrogen juga sangat dekat dengan oksigen (Rahm et al., 2016). Tujuan dari penelitian ini adalah mempelajari pengaruh doping $\mathrm{Zn}$ dan $\mathrm{N}$ pada struktur geometri dan elektronik $\mathrm{TiO}_{2}$ anatas menggunakan perhitungan density fuctional theory (DFT).

\section{Metode Penelitian}

Model Komputasi

Dalam penelitian ini digunakan
supercell $\mathrm{TiO}_{2}$ anatas $2 \times 2 \times 1$ yang mengandung 48 atom dan memiliki simetri I4 1 /amd. Untuk membangun sistem monodoping substitusional, satu atom $\mathrm{N}$ dopan menempati lokasi kisi atom 0 , sedangkan satu atom Ti digantikan oleh satu atom $\mathrm{Zn}$. Untuk sistem co-doping $\mathrm{Zn}-\mathrm{N}$, satu atom $\mathrm{Ti}$ dan $\mathrm{O}$ diganti masing-masing dengan satu atom $\mathrm{Zn}$ dan satu atom N. Konsentrasi atom mono-doping sekitar 2,08 \% dan co-doping Zn-N sekitar 4,16 \% ditunjukkan pada Gambar 1.
Metode Komputasi

Semua perhitungan didasarkan pada density fuctional theory (DFT) menggunakan pseudopotensial projector augmented wave (PAW) yang diterapkan dalam perangkat lunak Quantum-ESPRESSO. (Giannozzi et al., 2009). Fungsi korelasi pertukaran menggunakan generalized gradient approximation (GGA) dengan parameterisasi Perdew-Burke-Ernzerhof (PBEsol) (Perdew et al., 2008). Energi cut-off 703,06 eV digunakan untuk fungsi gelombang dan 7830,67 eV untuk kerapatan muatan. Optimasi struktur menggunakan skema Broyden-Fletcher-Goldfarb-Shanno (BFGS). Pengambilan sampel zona brillouin digunakan $2 \times 2 \times 2 k$-point grid untuk optimasi struktur geometri dan $5 \times 5 \times 5 k$-point grid untuk perhitungan struktur elektronik yang dihasilkan sesuai dengan skema MonkhorstPack (Pack \& Monkhorst, 1977). Dalam perhitungan struktur elektronik digunakan GGA + U dengan parameter $U$ (Hubbard) $8 \mathrm{eV}$ pada Ti $3 d$ (R. Q. Li et al., 2019).
(A)

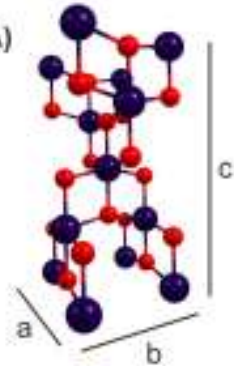

(C)

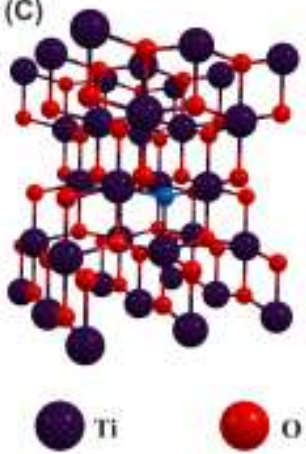

(B)

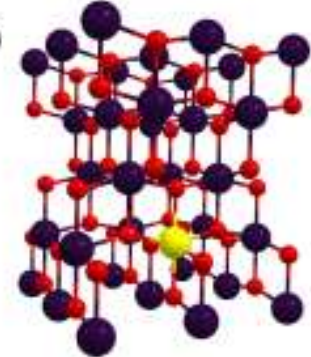

(D)

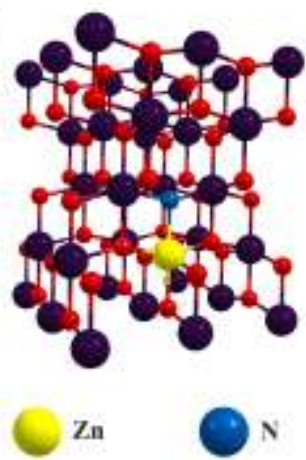

Gambar 1. Unitcell dan tiga konfigurasi doping untuk supercell $2 \times 2 \times 1 \mathrm{TiO}_{2}$ anatas (A) unitcell $\mathrm{TiO}_{2}$ (B) konfigurasi $\mathrm{TiO}_{2} @ \mathrm{Zn},(\mathrm{C})$ konfigurasi $\mathrm{TiO}_{2} @ \mathrm{~N}$ dan (D) konfigurasi $\mathrm{TiO}_{2} @ \mathrm{ZnN}$ 


\section{Hasil Penelitian dan Pembahasan}

\section{Struktur Geometri}

Struktur geometri mengalami perubahan disebabkan oleh pengaruh dopan. Penelitian ini membandingkan parameter kisi $\mathrm{TiO}_{2}$ murni yang telah dioptimasi dengan eksperimen. Parameter kisi yang dioptimasi ditunjukkan pada Tabel 1. parameter kisi $\mathrm{TiO}_{2}$ murni setelah dioptimasi sebesar $(\mathrm{a}=\mathrm{b}$ $=3,778 \AA, c=9,524 \AA$ ) mendekati dengan data eksperimen $(\mathrm{a}=\mathrm{b}=3,785 \AA \mathrm{A}, \mathrm{c}=9,520$ $\AA ̊)$ dengan perubahan volume kisi sebesar $0,447 \AA$.

Tabel 1. Parameter kisi, volume kisi dan perubahan kisi $\mathrm{TiO}_{2}$ anatas setelah optimasi

\begin{tabular}{ccccc}
\hline Struktur & $\begin{array}{c}\mathbf{a}=\mathbf{b} / \\
\AA\end{array}$ & $\mathbf{c} / \AA$ & $\mathbf{V} / \AA$ & $\Delta \mathbf{V} / \AA$ \\
\hline $\begin{array}{c}\text { Eksperimen } \\
\text { (Rezaee et }\end{array}$ & $\begin{array}{c}\mathbf{A}, 78 \\
\text { al., 2011) }\end{array}$ & $\begin{array}{c}9,52 \\
0\end{array}$ & $\begin{array}{c}136,3 \\
85\end{array}$ & - \\
\hline $\mathrm{TiO}_{2}$ & 3,77 & 9,52 & 135,9 & - \\
& 8 & 4 & 38 & \\
\hline $\mathrm{TiO}_{2} @ \mathrm{Zn}$ & 3,77 & 9,60 & 136,9 & 1,011 \\
& 6 & 5 & 49 & \\
\hline $\mathrm{TiO}_{2} @ \mathrm{~N}$ & 3,78 & 9,55 & 137,1 & 1,209 \\
& 9 & 3 & 47 & \\
\hline $\mathrm{TiO}_{2} @ \mathrm{ZnN}$ & 3,80 & 9,49 & 137,5 & 1,646 \\
& 7 & 3 & 84 & \\
\hline
\end{tabular}

Struktur kristal akan berubah dalam model doping disebabkan radius atom yang berbeda. Jari-jari N lebih besar 0,09 Å dari pada atom 0 , sedangkan jari-jari $\mathrm{Zn}$ lebih kecil 0,35 Å dari pada atom Ti (Rahm et al., 2016). Sehingga volume kisi $\mathrm{TiO}_{2} @ N$ lebih besar dari pada $\mathrm{TiO}_{2} @ \mathrm{Zn}$. sedangkan untuk co-doping, volume kisinya lebih mengembang dibandingkan dengan doping tunggal yang ditunjukkan pada Tabel 1.

$\mathrm{TiO}_{2}$ anatas memiliki struktur simetris, dimana setiap atom Ti terikat pada empat tetangga atom 0 terdekat dan dua tetangga atom 0 lainnya dengan panjang ikatan masing-masing 1,931 ̊̊ dan 1,983 A. Pemasukan dopan $\mathrm{N}$ ke $\mathrm{TiO}_{2}$ anatas mengarah pada pemanjangan jarak Ti-N tanpa merusak simetri. Pemasukan dopan Zn juga menyebabkan pemanjangan ikatan $\mathrm{Zn}-\mathrm{O}$ tanpa merusak simetri. Sedangkan co-doping Zn dan $\mathrm{N}$ menyebabkan pemanjangan ikatan Zn-O, Z-N dan Ti-N. Struktur co-doping Zn-N sangat terdistorsi dibandingkan dengan $\mathrm{TiO}_{2}$ doping tunggal. Rata-rata jarak Zn-0 2,009 A Jarak Zn-N 1,997 Å sedangkan jarak Ti-N sebesar $2,028 \AA$.

Tabel 2. Rata-rata panjang ikatan setelah optimasi

\begin{tabular}{|c|c|c|c|c|}
\hline \multirow{2}{*}{ Struktur } & \multicolumn{4}{|c|}{ Panjang Ikatan $(\AA)$} \\
\hline & Ti-O & Ti-N & Zn-O & Zn-N \\
\hline $\mathrm{TiO}_{2}$ & 1,948 & - & - & - \\
\hline $\mathrm{TiO}_{2} @ \mathrm{Zn}$ & 1,939 & - & 2,034 & - \\
\hline $\mathrm{TiO}_{2} @ \mathrm{~N}$ & 1,941 & 2,036 & - & - \\
\hline $\mathrm{TiO}_{2} @ \mathrm{ZnN}$ & 1,963 & 2,028 & 2,009 & 1,997 \\
\hline
\end{tabular}

\section{Struktur Elektronik}

Gambar 2. Menunjukkan bahwa sistem $\mathrm{TiO}_{2}$ anatas murni adalah semikonduktor dengan celah pita langsung, yang dihitung di antara bagian atas pita konduksi dan bagian bawah pita valensi sebesar 3,18 eV. Nilai ini mendekati nilai eksperimen sebesar 3,2 eV (Reddy et al., 2003).

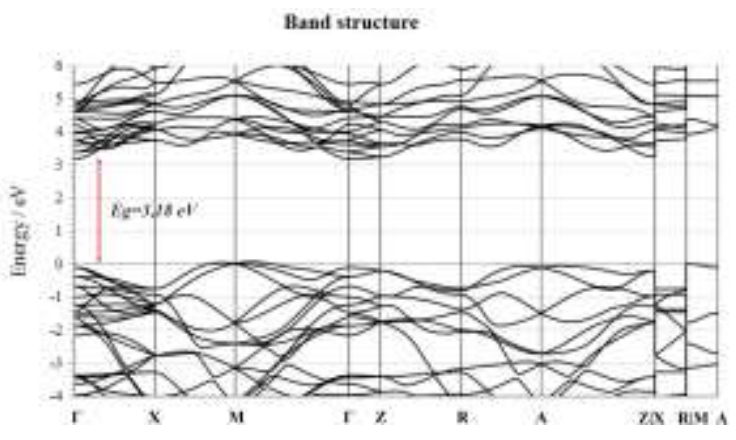

Gambar 2. Struktur pita $\mathrm{TiO}_{2}$ anatas menggunakan pendekatan GGA-PBEsol+ $U$

Penelitian ini menyajikan tiga konfigurasi doping yang menghasilkan tiga struktur elektronik yang berbeda, sehingga menghasilkan kinerja fotokatalitik tinggi di daerah cahaya tampak. Untuk menguji lebih jauh efek dari tiga model doping, peneliti memplot density of state (DOS) sistem $\mathrm{TiO}_{2}$ murni, $\mathrm{TiO}_{2} @ \mathrm{~N}, \mathrm{TiO}_{2} @ \mathrm{Zn}$ dan $\mathrm{TiO}_{2} @ \mathrm{ZnN}$ yang ditunjukkan pada Gambar 3. 
Dalam Gambar 3. menunjukkan pita valensi $\mathrm{TiO}_{2}$ murni sebagian besar dalam keadaan $02 p$ dengan kontribusi kecil dari keadaan Ti $3 d$. Sedangkan pita konduksi sebagian besar terdiri dari keadaan $\mathrm{Ti} 3 d$ dengan kontribusi kecil dari keadaan $02 p$. Hasil ini sangat konsisten dengan laporan dari beberapa penelitian sebelumnya (X. Li et al., 2017; R. Q. Li et al., 2019)

DOS $\mathrm{TiO}_{2} @ \mathrm{Zn}$ satu keadaan pengotor muncul di bawah pita valensi. Hal ini membuat tepi pita valensi sedikit bergeser ke arah pita konduksi sehingga mempersempit celah pita. Kemudian celah pita dari konfigurasi doping $\mathrm{Zn}$ menyempit menjadi 2,9 eV.

Untuk $\mathrm{TiO}_{2} @ \mathrm{~N}$ menghasilkan satu keadaan pengotor yang muncul di atas pita valensi. Hal ini membuat penyempitan celah pita, sehingga celah pita $\mathrm{TiO}_{2}$ doping $\mathrm{N}$ berkurang menjadi 2,78 eV. Selain mempersempit celah pita, keadaan pengotor di atas pita valensi dapat menerima elektron yang tereksitasi dari pita valensi dan kemudian mentransfernya ke pita konduksi dengan penyerapan energi yang lebih rendah. Lebih lanjut, keadaan ini termasuk keadaan pengontor dangkal (shallow impurity state), yang dapat menjebak photoexcited holes dan secara efektif dapat mengurangi rekombinasi elektron-hole. Oleh karena itu, keberadaan pengotor dari $\mathrm{N} 2 p$ ini akan secara signifikan meningkatkan kinerja fotokatalitik $\mathrm{TiO}_{2}$ di bawah daerah cahaya tampak.

Dalam kasus $\mathrm{TiO}_{2} @ \mathrm{ZnN}$ muncul tiga keadaan pengotor, satu dibagian atas pita valensi dan dua dibawah pita konduksi. Keadaan pengotor satu disebabkan oleh keadaan N $2 p$ Sedangkan dua pengotor lain disebabkan oleh $\mathrm{Zn} 3 d$ yang dapat menggeser sedikit kearah pita konduksi. Sehingga penyempitan celah pita menjadi 2,74 eV. Oleh karena itu, co-doping Zn dan N secara efektif dapat memperpanjang tepi absorpsi ke daerah cahaya tampak. Ada juga status pengotor terisolasi di dekat bagian bawah pita valensi yang termasuk ke dalam keadaan pengotor dangkal. Keadaan ini dapat menjebak photo-excited holes sehingga menghambat rekombinasi pasangan eletronhole yang bermanfaat bagi reaksi fotokatalitik.
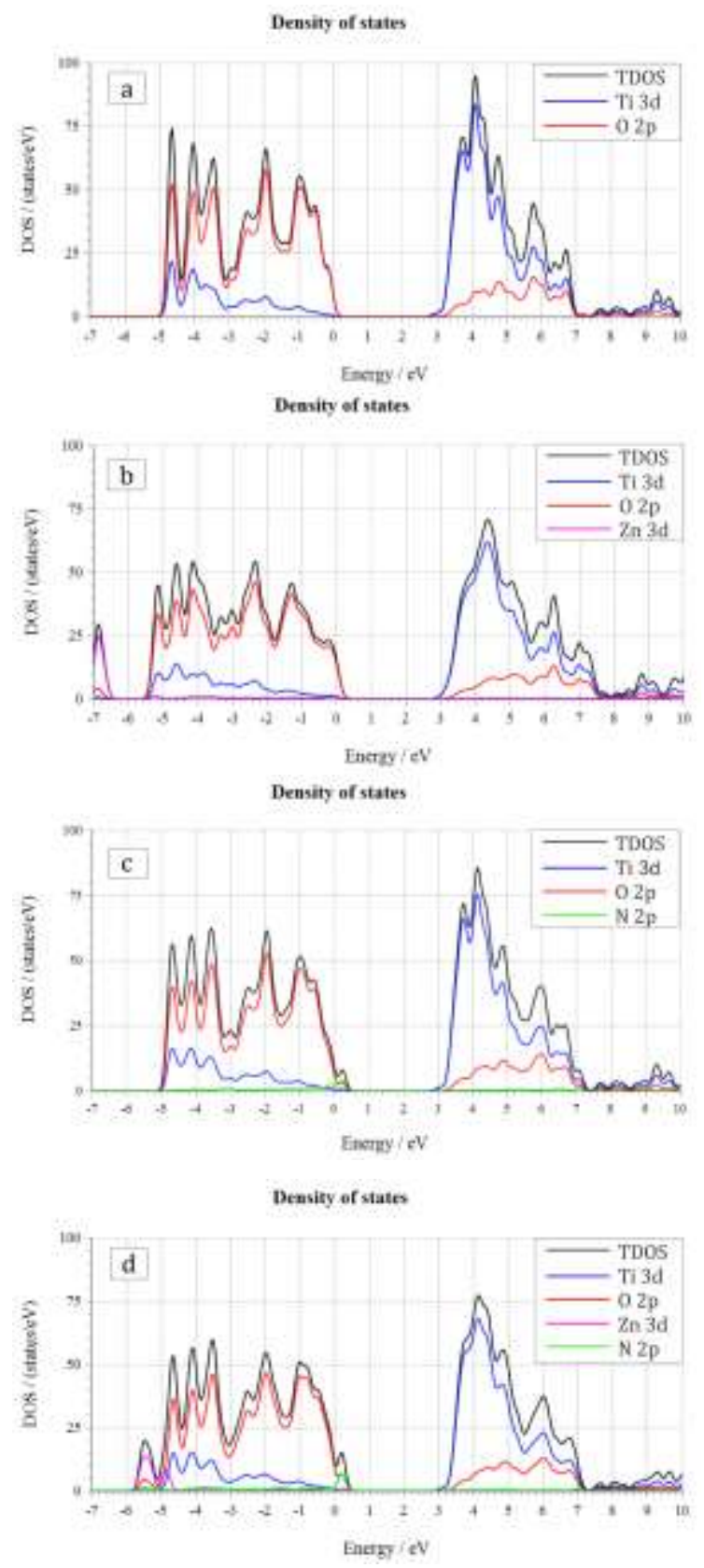

Gambar 3. Density of state (a) $\mathrm{TiO}_{2}$ murni (b) $\mathrm{TiO}_{2} @ \mathrm{~N}$ (c) $\mathrm{TiO}_{2} @ \mathrm{Zn}$ (d) $\mathrm{TiO}_{2} @ Z n N$ 


\section{Simpulan}

Efek doping menyebabkan distorsi struktural sehingga volume kisi $\mathrm{TiO}_{2}$ berubah, doping Zn 1,011 A, doping N 1,209 $\AA$ A dan co-doping Zn-N 1,646 À. Kemudian terjadi penyempitan celah pita $\mathrm{TiO}_{2}$ doping Zn 2,9 eV, doping $\mathrm{N} \mathrm{2,78} \mathrm{eV} \mathrm{dan} \mathrm{co-doping}$ $\mathrm{Zn}-\mathrm{N}$ 2,74 eV. Sehingga dapat menghambat rekombinasi pasangan elektron-hole dan secara signifikan akan meningkatkan aktivitas fotokatalitik $\mathrm{TiO}_{2}$ di daerah cahaya tampak.

\section{Daftar Pustaka}

Bayan, E. M., Lupeiko, T. G., Pustovaya, L. E., Volkova, M. G., Butova, V. V., \& Guda, A. A. (2020). Zn-F co-doped TiO2 nanomaterials: Synthesis, structure and photocatalytic activity. Journal of Alloys and Compounds, 822, 153662.

https://doi.org/10.1016/j.jallcom.2020 .153662

Chang, S. min, \& Liu, W. szu. (2014). The roles of surface-doped metal ions $(\mathrm{V}$, $\mathrm{Mn}, \mathrm{Fe}, \mathrm{Cu}, \mathrm{Ce}$, and $\mathrm{W}$ ) in the interfacial behavior of TiO2 photocatalysts.

Applied Catalysis B: Environmental, 156157, 466-475.

https://doi.org/10.1016/j.apcatb.2014. 03.044

Chen, H., Li, X., Wan, R., Kao-walter, S., Lei, Y., \& Leng, C. (2018). A DFT study on modification mechanism of $(\mathrm{N}, \mathrm{S})$ interstitial co-doped. Chemical Physics Letters, 695, 8-18. https://doi.org/10.1016/j.cplett.2018.0 1.044

Giannozzi, P., Baroni, S., Bonini, N., Calandra, M., Car, R., Cavazzoni, C., Ceresoli, D., Chiarotti, G. L., Cococcioni, M., Dabo, I., Dal Corso, A., De Gironcoli, S., Fabris, S., Fratesi, G., Gebauer, R., Gerstmann, U., Gougoussis, C., Kokalj, A., Lazzeri, M., ... Wentzcovitch, R. M. (2009). QUANTUM ESPRESSO: A modular and open-source software project for quantum simulations of materials. Journal of Physics Condensed Matter, 21(39). https://doi.org/10.1088/0953-

8984/21/39/395502

Gomes, J. F., Lopes, A., Bednarczyk, K., Gmurek, M., Stelmachowski, M., Zaleska-Medynska, A., Quinta-Ferreira, M. E., Costa, R., Quinta-Ferreira, R. M., \& Martins, R. C. (2018). Effect of noble metals (Ag, pd, pt) loading over the efficiency of tio2 during photocatalytic ozonation on the toxicity of parabens. ChemEngineering, 2(1), 1-14. https://doi.org/10.3390/chemengineer ing2010004

Jani, N. A., Haw, C., Chiu, W., Rahman, S. A., Khiew, P., Lim, Y., Abd-Shukor, R., \& Hamid, M. A. A. (2020). Photodeposition of Ag Nanocrystals onto TiO2 Nanotube Platform for Enhanced Water Splitting and Hydrogen Gas Production. Journal of Nanomaterials, 2020. https://doi.org/10.1155/2020/748036 7

Kuo, C. Y., Jheng, H. K., \& Syu, S. E. (2019). Effect of non-metal doping on the photocatalytic activity of titanium dioxide on the photodegradation of aqueous bisphenol A. Environmental Technology (United Kingdom), O(0), 124. https://doi.org/10.1080/09593330.20 19.1674930

Li, R. Q., Li, D. X., Zhou, D. T., Qin, X. M., \& Yan, W. J. (2019). Theoretical studies on the electronic structures and optical properties of $(\mathrm{Cu}, \mathrm{C})$-codoped rutile $\mathrm{TiO}$ 2 from GGA+U calculations. Journal of Molecular Graphics and Modelling, 90, 104-108.

https://doi.org/10.1016/j.jmgm.2019.0 4.002

Li, X., Shi, J., Chen, H., Wan, R., Leng, C., Chen, S., \& Lei, Y. (2017). A DFT study on the modification mechanism of $(\mathrm{Cr}, \mathrm{C})$ codoping for the electronic and optical properties of anatase $\mathrm{TiO} 2$.

Computational Materials Science, 129, 295-303.

https://doi.org/10.1016/j.commatsci.2 016.12.029 
Lin, Y., Jiang, Z., Zhu, C., Zhang, R., Hu, X., Zhang, X., Zhu, H., \& Lin, S. H. (2017). The electronic structure, optical absorption and photocatalytic water splitting of $(\mathrm{Fe}+\mathrm{Ni})$-codoped TiO2: A DFT + U study. International Journal of Hydrogen Energy, 42(8), 4966-4976. https://doi.org/10.1016/j.ijhydene.201 6.06.077

Liu, X., Li, Y., Wei, Z., \& Shi, L. (2018). A Fundamental DFT Study of Anatase (TiO2) Doped with 3d Transition Metals for High Photocatalytic Activities. Journal Wuhan University of Technology, Materials Science Edition, 33(2), 403408. https://doi.org/10.1007/s11595018-1836-5

Pack, J. D., \& Monkhorst, H. J. (1977). “special points for Brillouin-zone integrations"-a reply. Physical Review B, 16(4), 17481749.

https://doi.org/10.1103/PhysRevB.16. 1748

Perdew, J. P., Ruzsinszky, A., Csonka, G. I., Vydrov, O. A., Scuseria, G. E., Constantin, L. A., Zhou, X., \& Burke, K. (2008). Restoring the density-gradient expansion for exchange in solids and surfaces. Physical Review Letters, 100(13), 1-4. https://doi.org/10.1103/PhysRevLett.1 00.136406

Pragathiswaran, C., Smitha, C., Barabadi, H., Al-Ansari, M. M., Al-Humaid, L. A., \& Saravanan, M. (2020).TiO2@ZnO nanocomposites decorated with gold nanoparticles: Synthesis, characterization and their antifungal, antibacterial, anti-inflammatory and anticancer activities. Inorganic Chemistry Communications, 121(August), 108210. https://doi.org/10.1016/j.inoche.2020. 108210

Rahm, M., Hoffmann, R., \& Ashcroft, N. W. (2016). Atomic and Ionic Radii of Elements 1-96. Chemistry - A European Journal, 22(41), 14625-14632. https://doi.org/10.1002/chem.201602
949

Reddy, K. M., Manorama, S. V., \& Reddy, A. R. (2003). Bandgap studies on anatase titanium dioxide nanoparticles.

Materials Chemistry and Physics, 78(1), 239-245. https://doi.org/10.1016/S02540584(02)00343-7

Rezaee, M., Mousavi Khoie, S. M., \& Liu, K. H. (2011). The role of brookite in mechanical activation of anatase-torutile transformation of nanocrystalline Ti02: An XRD and Raman spectroscopy investigation. CrystEngComm, 13(16), 5055-5061. https://doi.org/10.1039/c1ce05185g

Schneider, J., Matsuoka, M., Takeuchi, M., Zhang, J., Horiuchi, Y., Anpo, M., \& Bahnemann, D. W. (2014). Understanding TiO2photocatalysis: Mechanisms and materials. Chemical Reviews, 114(19), 9919-9986. https://doi.org/10.1021/cr5001892

Shalini, S., Kumar, T. S., Prasanna, S., \& Balasundaraprabhu, R. (2020). Investigations on the effect of co-doping in enhancing the performance of nanostructured TiO2 based DSSC sensitized using extracts of Hibiscus Sabdariffa calyx. Optik, 212(March). https://doi.org/10.1016/j.ijleo.2020.16 4672

Sun, M., Liu, H., Sun, Z., \& Li, W. (2020). Donor-acceptor codoping effects on tuned visible light response of $\mathrm{TiO}$. Journal of Environmental Chemical Engineering, 8(5), 104168. https://doi.org/10.1016/j.jece.2020.10 4168

Tehare, K. K., Bhande, S. S., Mutkule, S. U., Stadler, F. J., Ao, J. P., Mane, R. S., \& Liu, X. (2017). Low-temperature chemical synthesis of rutile and anatase mixed phase TiO2nanostructures for DSSCs photoanodes. Journal of Alloys and Compounds, 704, 187-192. https://doi.org/10.1016/j.jallcom.2017 .01 .358 
Wu, H. C., Lin, S. W., \& Wu, J. S. (2012). Effects of nitrogen concentration on $\mathrm{N}$-doped anatase TiO 2: Density functional theory and Hubbard $\mathrm{U}$ analysis. Journal of Alloys and Compounds, 522, 46-50. https://doi.org/10.1016/j.jallcom.2012 .01 .071

Yuan, R., Liu, D., Wang, S., Zhou, B., \& Ma, F. (2018). Enhanced photocatalytic oxidation of humic acids using Fe3+$\mathrm{Zn} 2+$ co-doped TiO2: The effects of ions in aqueous solutions. Environmental Engineering Research, 23(2), 181-188. https://doi.org/10.4491/eer.2017.062 